Type of Article: Original Article

Title:

\title{
The Birth Satisfaction Scale-Revised Indicator (BSS-RI): A Validation Study in Iranian Mothers
}

Authors:

Reza Omani-Samani ${ }^{1}$, Caroline J. Hollins Martin $^{2}$, Colin R. Martin ${ }^{3}$, Saman Maroufizadeh $^{4 *}$, Azadeh Ghaheri ${ }^{5}$, Behnaz Navid $^{5}$

\author{
Affiliations: \\ ${ }^{1}$ Department of Medical Ethics and Law, Reproductive Biomedicine Research Center, Royan \\ Institute for Reproductive Biomedicine, ACECR, Tehran, Iran. \\ ${ }^{2}$ School of Nursing, Midwifery and Social Care, Edinburgh Napier University, Edinburgh, UK. \\ ${ }^{3}$ Faculty of Society and Health, Buckinghamshire New University, Uxbridge, UK. \\ ${ }^{4}$ School of Nursing and Midwifery, Guilan University of Medical Sciences, Rasht, Iran. \\ ${ }^{5}$ Department of Epidemiology and Reproductive Health, Reproductive Epidemiology Research \\ Center, Royan Institute for Reproductive Biomedicine, ACECR, Tehran, Iran \\ *Corresponding Author: Saman Maroufizadeh \\ School of Nursing and Midwifery, Guilan University of Medical Sciences, Rasht, Iran. \\ Tel: +98-9351559663; Email: saman.maroufizadeh@gmail.com
}

Emails:

Reza Omani-Samani, Email: samani@ royaninstitute.org

Caroline J. Hollins Martin, Email: C.HollinsMartin@napier.ac.uk

Colin R. Martin, Email: colin.martin@bucks.ac.uk

Saman Maroufizadeh, Email: saman.maroufizadeh@gmail.com

Azadeh Ghaheri, Email: ghaheri@ royaninstitute.org

Behnaz Navid, Email: behnaz_navid@ yahoo.com

Running Title: Validation Study of the BSS-RI

Words Count: Main Text: 1863 and Abstract: 236

Number of Tables: 3, Number of Figures: 0 


\title{
The Birth Satisfaction Scale-Revised Indicator (BSS-RI): A Validation Study in Iranian Mothers
}

\begin{abstract}
Objective: Birth Satisfaction Scale-Revised Indicator (BSS-RI) is a short self-report instrument designed to measure satisfaction of the childbearing women's experiences of labour and its outcomes. The aim of this study was to examine the reliability and validity of the Persian version of BSS-RI in Iranian mothers.

Methods: This cross-sectional study was conducted on 396 mothers in Tehran, Iran, between July and September, 2017. The mothers were administered the BSS-RI, and a demographic questionnaire. Internal consistency of the BSS-RI was examined with Cronbach's alpha, construct validity was evaluated via exploratory factor analysis (EFA), and divergent validity was examined by correlating the BSS-RI with gestational age.

Results: The EFA results demonstrated a two-factor structure corresponding to the Stress of Childbearing and Quality of Care domains of the structure proposed by provider. The Cronbach's alpha for Stress of Childbearing and Quality of Care subscales and total BSS-RI were $0.665,0.847$, and 0.563 , respectively. The mean of BSS-RI total score was $6.16(\mathrm{SD}=2.60)$, and the Stress of Childbearing and Quality of Care subscales were 2.71 ( $\mathrm{SD}=2.39$ ), and 3.45 $(\mathrm{SD}=1.11)$, respectively. The BSS-RI showed no significant correlation with the gestational age, confirming divergent validity.

Conclusion: Like the original English version, the Persian version of the BSS-RI is a reliable and valid instrument for measuring birth satisfaction in Iranian mothers. It can also be used as short and easy to administer tool for assessment of birth satisfaction in large sample survey research.
\end{abstract}

Keywords: Birth Satisfaction, Labour, Reliability, Validity, Iran 


\section{Introduction}

One of the most important outcome measures for provision of health care services and the quality of care is the individuals' satisfaction [1]. Giving birth to a child is considered a unique experience in most of the mothers' lives; on the other hand, a women's level of satisfaction with this experience influences theirs and their newborns' health and wellbeing as well as their relationship [2]. Therefore, evaluation of childbearing women's satisfaction from obstetric services during intra-partum, and postpartum period can help policymakers to improve the quality of health care services [3].

A series of reforms have been launched in 2014 in Iran to make some improvements in the health system performance. The changes which were designed by the Ministry of Health and Medical Education were called Health Sector Evolution Plan (HSEP) [4]. Consistent with HSEP's focus on maternal and infant health, light should be shed on childbearing women's level of birth satisfaction and its psychological dimensions as well.

Birth satisfaction varies according to each individual's personal preferences and expectations and this makes the objective assessment of birth satisfaction multidimensional and challenging [5]. A range of measures were developed to assess satisfaction with the childbirth experience. However, Sawyer and colleagues highlighted that many of these measures were not based on the main theoretical models of satisfaction [6].

The Birth Satisfaction Scale (BSS), a self-report questionnaire, was developed by Hollins Martin and Fleming to assess women's perceptions of birth. The original English 30-item BSS was developed for inclusive use within the birth context using thematic review of the research literature and evidence-based reports of women's birth satisfaction [7]. The long form of scale was then followed by a 10-item form (BSS-R) assessing three domains: Quality of Care, Women's Attributes and Stress Experienced [8]. While both BSS and BSS-R showed to measure psychological dimensions of satisfaction in a valid and reliable way, simplifying the instrument and reducing the number of items in order to function as an indicator was desirable. The six item Birth Satisfaction Scale-Revised Indicator (BSS-RI) was found to have excellent psychometric properties in the UK, representing an easily administered measure while providing information which is psychologically plausible [9]. 
To the best of our knowledge, no studies were done in Iran to assess psychometrics properties of the Persian version of the BSS-RI. Therefore, this study was conducted to evaluate the reliability and validity of BSS-RI in Iranian mothers.

\section{Material and Methods}

\section{Participants and study design}

In this cross-sectional study, mothers referring to health center for neonatal vaccination in Tehran, Iran were invited to take part in the study. The data were collected through the convenience sampling method between July and September 2017. Mothers had to meet the following criteria to be eligible for the study: (1) women; (2) willingness to participate in the study; (3) had given birth in hospital or birthing center in Tehran during the last 2 years; and (4) ability to read, write in Persian. In total, 396 mothers agreed to take part and filled out the questionnaires completely.

\section{Ethical approval}

This study was approved by the Ethics Committee of Royan Institute, Tehran, Iran. The aim and objective of the study and confidentiality of the data were explained verbally to the women by the researcher prior to their participation. Moreover, written informed consent was obtained from all mothers before completing the measures.

\section{Translation of the BSS-RI into Persian}

The standard "forward-backward" translation procedure was used to translate the BSS-RI from English into Persian. The questionnaire was translated into Persian by two native Persian researchers, both of whom were fluent in oral and written English. The two forward translations were compared and synthesized into one common version by the research team. This version was then back-translated by a bilingual expert who had no knowledge of the wording of the original English version of the BSS-RI. The two English versions were then compared and minor discrepancies were corrected. Ten mothers were asked to complete the provisional version of BSS-R as a pilot study. Further corrections were subsequently completed, and the final version was made available for this research. 


\section{Measures}

Demographic information and obstetrics factors of the mother

Basic demographic and obstetrics characteristics of mother included: age, level of education, employment status, duration of marriage, type of delivery, gestational age, duration of labor, and parity.

\section{Birth Satisfaction Scale-Revised Indicator (BSS-RI)}

The BSS-RI is a short form of Birth Satisfaction Scale (BSS) which is a 6-item self-report instrument composed of two domains: Stress of Childbearing (4 Items), and Quality of Care (2 Items). Items are scored on a 3-point Likert scale ("disagree" =0, "agree to some degree" =1, and "agree" =2). Three of the items are reverse-coded (item BSS-RI 2, BSS-RI 4, and BSS-RI 5). Total scores and subscales scores can range as follows: BSS-RI: 0-12, Stress of Childbearing: 08, and Quality of Care: 0-4, with higher scores indicating greater levels of birth satisfaction.

\section{Data analysis}

To examine the factor structure of the BSS-RI, we conducted an exploratory factor analysis (EFA) using principal component method with varimax rotation. First, appropriateness of EFA was determined by examining the Kaiser-Meyer-Olkin (KMO) measure of sampling adequacy and the Bartlett's test of sphericity. A KMO value above 0.5 and a significant Bartlett's Test of Sphericity justifies the use of factor analysis. Internal consistency of the BSS-RI was examined using Cronbach's alpha coefficient. The divergent validity of the BSS-RI was examined by calculating Pearson correlation coefficient between the BSS-RI scores and mother's age. It was predicted that there would be no significant relationship between BSS-RI scores and the mother's age. Known-groups validity using $\mathrm{t}$ test comparing birth satisfaction across delivery type (vaginal vs. Caesarean section) was performed. Data analyses were performed with SPSS version 16 for windows (SPSS Inc., Chicago, IL, USA). All statistical tests were two-sided and the level of statistical significance was set at 0.05 .

\section{Results}

\section{Mothers characteristics}


Demographic and obstetrics characteristics of the mothers are presented in Table 1. The mean age of mothers was 30.13 ( $\mathrm{SD}=5.81$ ) years with a range of 16-45. The mean duration of pregnancy was 38.40 ( $\mathrm{SD}=1.63)$ weeks. Of the mothers, $29.8 \%$ were university-educated, $12.9 \%$ were employed, $57.6 \%$ were multiparous. The average duration of labour was 5.92 (SD 14.63) hours. CS was reported for $72.7 \%$ of the sample (of which $65.3 \%$ reported planned CS).

Table 1 Demographic and obstetrics characteristics of the mothers $(n=396)$.

\section{Exploratory factor analysis}

The KMO measure of sampling adequacy ( 0.60$)$ and the Bartlett test of sphericity ( $\chi^{2}=621.82$, $\mathrm{df}=15, \mathrm{P}<0.001)$ indicated the appropriateness of factor analysis. The EFA results indicated that there were two underlying dimensions (factors), explaining $64.91 \%$ of variances. Similar to Original English version, the factors were named, "Stress of Childbearing" (4 items), and "Quality of Care" (2 items). The item factor loadings, eigenvalues and explained variance are shown in Table 2.

Table 2 Results of the EFA using principal component method with varimax rotation for BSS-RI in Iranian mothers $(\mathrm{n}=396)$

\section{Descriptive statistics of the BSS-RI}

Table 3 shows the item wording and descriptive statistics of the BSS-RI and its domains. The item means ranged from 0.53 to 1.73 . The highest mean score on BSS-RI items was obtained for Quality of Care items (item 3 and 6). The mean (SD) scores of the BSS-RI, Stress of Childbearing domain, and Quality of Care domain were 6.16 (2.60), 2.71 (2.39), and 3.45 (1.11), respectively.

Table 3 Items wording, descriptive statistics of the BSS-RI

\section{Internal Consistency}


Cronbach's alpha coefficients for assessing internal consistency of the BSS-RI and its domains were as follows: Stress of Childbearing domain (4 items, 0.665), Quality of Care domain (2 items, 0.847), and BSS-RI total score (6 items, 0.563).

\section{Divergent validity}

As expected, correlation analysis showed that mother's age was not related to BSS-RI total score $(r=0.010, p=0.838)$, Stress of Childbearing domain score $(r=0.010, p=0.839)$, and Quality of Care domain score $(\mathrm{r}=0.008, \mathrm{p}=0.867)$.

\section{Known groups validity}

According to the $\mathrm{t}$ test results, there were no differences across delivery type on the BSS-RI $(\mathrm{P}=0.868)$, Stress of Childbearing $(\mathrm{P}=0.672)$, and Quality of Care $(\mathrm{P}=0.771)$.

\section{Discussion}

To the best of our knowledge, this is the first study to examine the reliability and validity of the BSS-RI in Iranian mothers. The BSS-RI is a brief and easy to use instrument and considered a parsimonious alternative to longer forms. Like the UK sample, the highest mean score on BSSRI items was obtained for Quality of Care items. In addition, the mean of Quality of Care domain (M=3.45) was consistent with what was reported in UK population (Mean=3.46), whereas the mean of Stress of Childbearing domain $(M=2.71)$ was considerably lower than the UK population ( $M=4.74)$ [9]. These results suggesting that Iranian mothers report on average higher levels of stress compared to the UK sample.

In line with what was reported in original study in UK mothers [9], EFA provided support for a two-factor structure of BSS-RI. Taking the brevity of the BSS-RI and its domains into account, the internal consistency reliability of the BSS-RI was relatively satisfactory. The obtained Cronbach's alpha values are in line with what was reported in original study in UK population [9].

Contrary to our expectation, there were no differences across delivery type (vaginal vs. CS) on the BSS-RI and its domains. In the UK study [9], mothers experiencing a normal delivery having significantly higher BSS-RI scores compared to those experiencing non-normal delivery. 
Furthermore, in other studies, the BSS-R and BSS-30 demonstrated known-groups validity based on normal vs. non-normal deliveries [8, 10-12].

Divergent validity of the BSS-RI and its domains was confirmed via nonsignificant correlations with mother's age. In original study, no significant correlation was found between the BSS-RI scores and number of weeks pregnant at booking. In addition, similar trend has been found in previous studies on earlier form of BSS (i.e. BSS-30 and BSS-R) [8, 10-12].

Further validation studies are required on the BSS-RI in other Iranian sample so that researchers can begin to evaluate correlates and predictors of birth satisfaction in order to better address childbearing women's intrapartum needs.

Several limitations of the current study should be noted. First, regarding the scale, one of the limitations is the small number of items in the Quality of Care domain. It is recommended that number of items per factor should be at least three [13, 14]. Second, because of the crosssectional nature of the present study, causal inference between BSS-RI scores and demographic characteristics of mothers cannot be drawn. Third, for practical reasons, the test-retest reliability of the BSS-RI was not assessed in this study. Forth, similar to other studies in Iran $[15,16]$, the rate of CS was $72.7 \%$ in this study, which is substantially higher than the worldwide average [17].

In sum, the BSS-RI is a reliable and valid tool for assessing birth satisfaction. This scale is a brief and easy to use instrument providing an economic tool for research, service evaluation and policy makers. Furthermore, the EFA results provide support for the two-factor structure of the BSS-RI (i.e. Stress of Childbearing and Quality of Care domains) and use of the factors as discrete variables.

\section{Disclosure statement}

The authors declare that they have no conflict of interest.

\section{Funding}

This study was supported by Royan Institute for Reproductive Biomedicine, ACECR, Tehran, Iran.

\section{References}


1. Mattison CA, Dion ML, Lavis JN, Hutton EK, Wilson MG: Midwifery and obstetrics: Factors influencing mothers' satisfaction with the birth experience. Birth 2018, 45(3):322-327.

2. Goodman P, Mackey MC, Tavakoli AS: Factors related to childbirth satisfaction. J Adv Nurs 2004, 46(2):212-219.

3. Lewis L, Hauck YL, Ronchi F, Crichton C, Waller L: Gaining insight into how women conceptualize satisfaction: Western Australian women's perception of their maternity care experiences. BMC Pregnancy Childbirth 2016, 16(1):29.

4. Moradi-Lakeh M, Vosoogh-Moghaddam A: Health sector evolution plan in Iran; equity and sustainability concerns. Int J Health Policy Manag 2015, 4(10):637.

5. Srivastava A, Avan BI, Rajbangshi P, Bhattacharyya S: Determinants of women's satisfaction with maternal health care: a review of literature from developing countries. BMC Pregnancy Childbirth 2015, 15(1):97.

6. Sawyer A, Ayers S, Abbott J, Gyte G, Rabe H, Duley L: Measures of satisfaction with care during labour and birth: a comparative review. BMC Pregnancy Childbirth 2013, 13(1):108.

7. Hollins Martin C, Fleming V: The birth satisfaction scale. Int J Health Care Qual Assur 2011, 24(2):124-135.

8. Martin $\mathrm{CJH}$, Martin CR: Development and psychometric properties of the Birth Satisfaction Scale-Revised (BSS-R). Midwifery 2014, 30(6):610-619.

9. Martin CR, Martin CH, Redshaw M: The Birth Satisfaction Scale-Revised Indicator (BSS-RI). BMC Pregnancy Childbirth 2017, 17(1):277.

10. Vardavaki Z, Hollins Martin CJ, Martin CR: Construct and content validity of the Greek version of the Birth Satisfaction Scale (G-BSS). J Reprod Infant Psychol 2015, 33(5):488-503.

11. Barbosa-Leiker C, Fleming S, Hollins Martin CJ, Martin CR: Psychometric properties of the Birth Satisfaction Scale-Revised (BSS-R) for US mothers. J Reprod Infant Psychol 2015, 33(5):504-511.

12. Jefford E, Hollins Martin CJ, Martin CR: Development and validation of the Australian version of the Birth Satisfaction Scale-Revised (BSS-R). J Reprod Infant Psychol 2018, 36(1):42-58.

13. Kline R: Principles And Practice Of Structural Equation Modeling, 2nd edn. New York: Guilford Press; 2005.

14. Raubenheimer J: An item selection procedure to maximize scale reliability and validity. SA J Ind Psychol 2004, 30(4):59-64.

15. Omani-Samani R, Mohammadi M, Almasi-Hashiani A, Maroufizadeh S: Cesarean Section and Socioeconomic Status in Tehran, Iran. J Res Health Sci 2017, 17(4):e00394.

16. Amini P, Mohammadi M, Omani-Samani R, Almasi-Hashiani A, Maroufizadeh S: Factors Associated with Cesarean Section in Tehran, Iran using Multilevel Logistic Regression Model. Osong Public Health Res Perspect 2018, 9(2):86-92.

17. Betrán AP, Ye J, Moller A-B, Zhang J, Gülmezoglu AM, Torloni MR: The increasing trend in caesarean section rates: global, regional and national estimates: 1990-2014. PloS one 2016, 11(2):e0148343. 
Table 1 Demographic and obstetrics characteristics of the mothers $(n=396)$.

mean \pm SD or $n(\%)$

$\begin{array}{ll}\text { Mother's age (years) } & 30.13 \pm 5.81 \\ \text { Educational level } & 278(70.2) \\ \quad \text { Primary/Secondary } & 118(29.8) \\ \quad \text { University } & 345(87.1) \\ \text { Occupation } & 51(12.9) \\ \quad \text { Housewife } & 7.96 \pm 5.44 \\ \quad \text { Employed } & 38.40 \pm 1.63 \\ \text { Duration of marriage (years) } & 5.92 \pm 14.63 \\ \text { Duration of pregnancy (weeks) } & \\ \text { Duration of labour (hours) } & 168(42.4) \\ \text { Parity } & 228(57.6) \\ \quad \text { Primiparous } & 108(27.3) \\ \quad \text { Multiparous } & 288(72.7) \\ \text { Delivery mode } & \\ \quad \text { Vaginal } & 188(65.3) \\ \text { Cesarean } & 100(34.7) \\ \text { Type of Cesarean section (n=288) } & \\ \text { Planned } & 336(84.8) \\ \text { Emergency } & 60(15.2) \\ \text { Type of pregnancy } & \\ \quad \text { Wanted } & 201(50.8) \\ \text { Unwanted } & 195(49.2) \\ \text { Infant sex } & \end{array}$

SD: Standard deviation 
Table 2 Results of the EFA using principal component method with varimax rotation for BSS-RI in Iranian mothers $(n=396)$.

\begin{tabular}{llll}
\hline & & $\begin{array}{l}\text { Factor 1 (Stress of } \\
\text { Childbearing) }\end{array}$ & $\begin{array}{l}\text { Factor 2 (Quality } \\
\text { of Care) }\end{array}$ \\
\hline 1 & I was not distressed at all during labour & 0.50 & \\
2 & I felt very anxious during my labour and birth (R) & 0.73 & \\
4 & I found giving birth a distressing experience (R) & 0.83 & \\
5 & I felt out of control during my birth experience (R) & 0.76 & 0.91 \\
3 & I felt well supported by staff during my labour and birth & & 0.90 \\
6 & The staff communicated well with me during labour & & 1.79 \\
& & 2.10 & 30.70 \\
& Eigenvalue & \\
& \% of Total Variance & 34.21 & \\
\hline
\end{tabular}

R: Reversed item 
Table 3 Items wording, descriptive statistics of the BSS-RI

\begin{tabular}{|c|c|c|c|c|}
\hline & & Domain & Mean & SD \\
\hline 1 & I was not distressed at all during labour & Stress & 0.62 & 0.85 \\
\hline 2 & I felt very anxious during my labour and birth (R) & Stress & 0.53 & 0.79 \\
\hline 3 & I felt well supported by staff during my labour and birth & Quality & 1.73 & 0.58 \\
\hline 4 & I found giving birth a distressing experience $(\mathrm{R})$ & Stress & 0.67 & 0.87 \\
\hline 5 & I felt out of control during my birth experience (R) & Stress & 0.90 & 0.88 \\
\hline \multirow[t]{4}{*}{6} & The staff communicated well with me during labour & Quality & 1.72 & 0.61 \\
\hline & Stress of Childbearing & & 2.71 & 2.39 \\
\hline & Quality of Care & & 3.45 & 1.11 \\
\hline & BSS-RI total score & & 6.16 & 2.60 \\
\hline
\end{tabular}

Note: R, reverse-coded items.

SD: Standard deviation 